|| Print ISSN: 2589-7837 || Online ISSN: 2581-3935 ||

International Journal of Medical Science and Diagnosis Research (IJMSDR)

Available Online at www.ijmsdr.com

NLM (National Library of Medicine ID: 101738824)

Case study

Volume 5, Issue 8; August:2021; Page No. 07-10

\title{
Uterine Rupture at a Site Distant From Old Scar: An Unusual Presentation
}

\author{
Poonam Shakya $^{1}$, Sonam Jindal ${ }^{2}$, Avir Sarkar ${ }^{1}$, Ankita Yadav', JC Sharma ${ }^{3}$ \\ ${ }^{1}$ Senior Resident, Department of Obstetrics and Gynecology, ESIC Medical College and Hospital, \\ Faridabad \\ ${ }^{2}$ Assistant Professor, Department of Obstetrics and Gynecology, ESIC Medical College and Hospital, \\ Faridabad \\ ${ }^{3}$ Professor and Head, Department of Obstetrics and Gynecology, ESIC Medical College and Hospital, \\ Faridabad
}

\section{Conflicts of Interest: Nil}

Corresponding author: Dr. Avir Sarkar

DOI: https://doi.org/10.32553/ijmsdr.v5i8.835

\begin{abstract}
:
Uterine rupture is a rare life threatening emergency with severe obstetric consequences. Most ruptures occur in a scarred uterus at the site of previous transmyometrial surgical incision. However, rupture on site distant from previous scar is a very rare entity. It is associated with major maternal and neonatal morbidity than rupture at a scarred area. Index case describes a scenario where uterine rupture occurred at the fundal region, far away from previous caesarean scar site leading to fetal demise. Till now, only a very few cases with uterine rupture away from the site of previous caesarean scar have been reported.

Keywords: uterine rupture, unscarred uterus, acute abdomen, hemoperitoneum
\end{abstract}

\section{Introduction:}

Uterine rupture is a rare but life threatening event. Most ruptures occur at sites of previous scars, mostly transmyometrial incisions of previous caesarean section, myomectomy or perforation following vigorous dilatation and curettage. It is very rare to witness a rupture away from the previous uterine scar site. Only very few cases have been reported till date. Rupture of an unscarred area of uterus is estimated to occur in $1 / 5700$ to $1 / 20,000$ pregnancies [1], which roughly accounts for $13 \%$ of all uterine ruptures [2]. Resource-poor countries witness most of these cases because prompt access to emergency caesarean and operative vaginal deliveries are not widely available here. Apart from previous interventions on uterus, other risk factors for spontaneous uterine rupture include cocaine abuse, previous instrumental delivery and vigorous fundal pressure during instrumentations in the endometrial cavity. This case report describes a rare case where uterine rupture occurred at a site quite distant from previous caesarean scar site in a multiparous woman, leading to abrupt fetal demise.

Case Report:

A 34-year old third gravida, with previous two caesarean deliveries, presented at gynecology casualty at 37 weeks gestation with diffuse lower abdominal pain. Previous 2 caesarean deliveries were conducted 14 and 10 years back respectively. On examination, she was conscious, but tachypneic, and was looking pale. She had tachycardia of 116/min and a blood pressure of $96 / 56 \mathrm{~mm} \mathrm{Hg}$ at admission. Her abdomen was distended with no uterine contour. Fetal parts were easily palpable. Fetal heart sounds were not localized with Doppler. However, no scar 
tenderness was elicited. An urgent bedside ultrasound showed a non-viable fetus with gross free fluid in abdomen and pelvis.

Emergency laboratory investigations were conducted. With a pre-operative hemoglobin of 7.2 grams/dl, packed red cells were arranged for transfusion intra-op. She was taken up for an urgent exploratory laparotomy. Intra-operatively, around 2.5 litres of hemoperitoneum was drained. An $8 \mathrm{~cm}$ transverse rent was observed at the region of the uterine fundus Figure 1 .

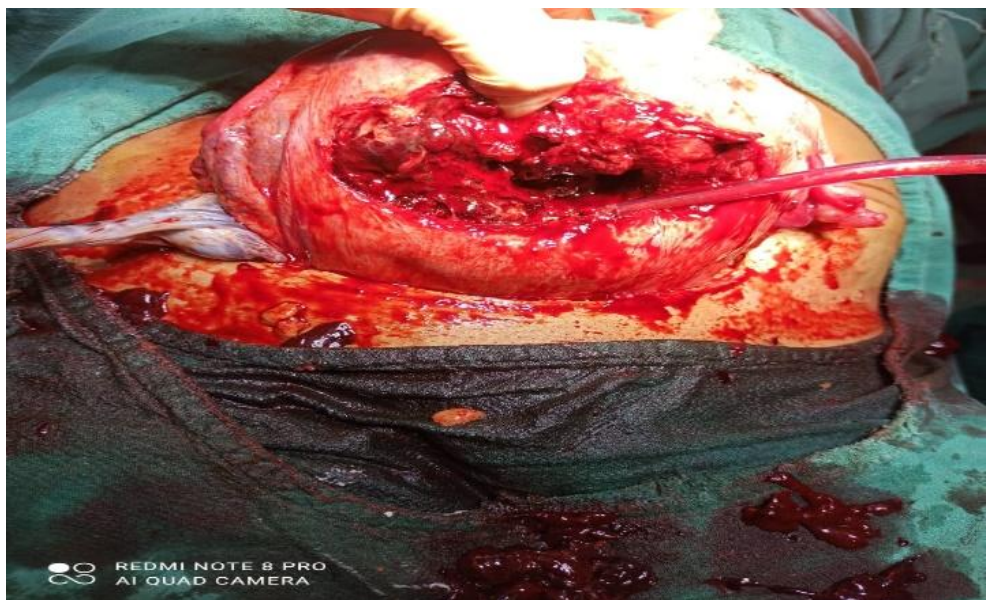

Figure 1: A transverse rent observed at the region of the uterine fundus, far from previous lower segment caesarean scar

Previous caesarean scar was intact. A $5 * 5 \mathrm{~cm}$ subserosal fibroid was seen on the posterior wall of the uterus in the lower uterine segment. Fetus along with placenta was lying in the abdominal cavity. After removing the fetus, placenta and all blood clots, uterine repair was done in 2 layers Figure 2

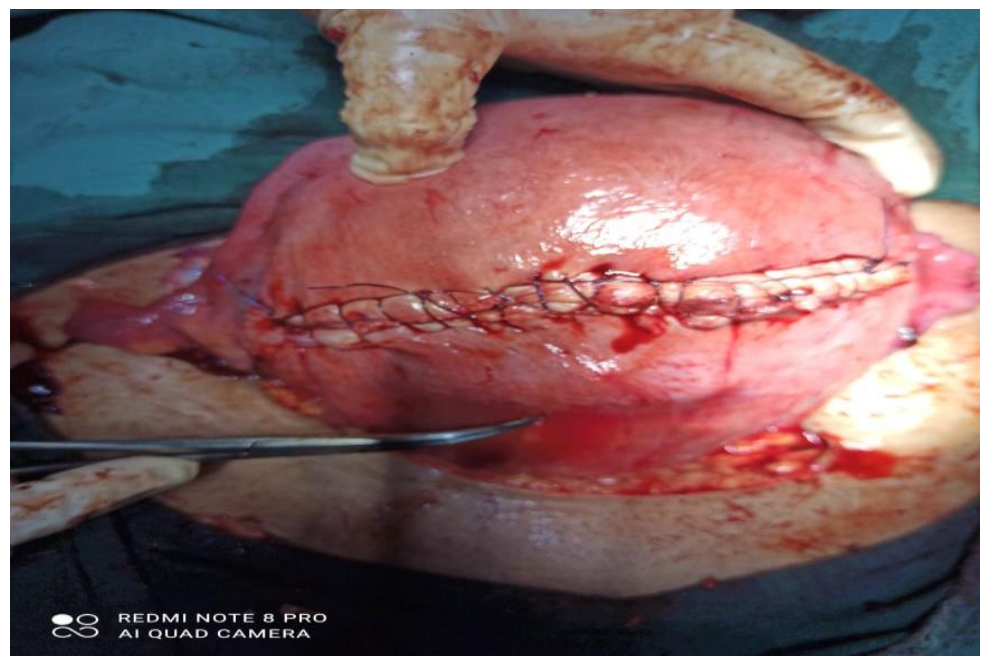

Figure 2: Repair of fundal rent done in 2 layers. Intact previous caesarean scar being shown by pointing with a pair of curved artery forceps

The fetus weighed $2.5 \mathrm{~kg}$ and did not show any signs of life. It was a fresh still born fetus with no signs of maceration (like peeling of skin).
Intraoperatively, two units of packed red blood cells and four units of fresh frozen plasma were transfused. Tubal ligation was done. Thorough 
saline washing of the peritoneal cavity was done followed by placement of an abdominal drain. After securing hemostasis, abdomen was closed in layers. Post-operative hemoglobin rose to 8.8 grams/dl. Her pulse and blood pressures normalized. Urine output was clear and adequate. She was intensively monitored in High Dependency Unit (HDU) for 3 days after surgery. Drain output was less than $100 \mathrm{ml}$ on first postoperative day, which reduced to $30 \mathrm{ml}$ the following day. So a decision was taken to omit it after 48 hours of surgery. On post-operative day 4 , she was shifted to general ward. She recovered gradually and was discharged at post-operative day 7 in stable condition.

\section{Discussion:}

Uterine rupture is defined as disruption of all layers of uterus. It can be either partial or complete. Scarred uterus remains the most important risk factor for rupture in next pregnancy. Almost all reported post-caesarean uterine ruptures $(99 \%)$ are generally located at old scar site [2]. Rupture of unscarred area of myometrium can be caused by external trauma to the abdomen or in cases of connective tissue disorders like Ehler-Danlos Syndrome or Marfan's Syndrome [3]. Prolonged use of uterotonic agents is also blamed to be a culprit in making the myometrium vulnerable to rupture [4]. Overdistension of the uterus may also be a provoking factor when myometrium is weakened due to some other reason.

Clinical presentations of uterine rupture mimic acute abdominal pain with features of vaginal bleeding, fetal bradycardia and a non-reassuring non-stress test (NST). Rarely, maternal hypotension can lead to hypovolemic shock. These features are more evident in lower segment uterine rupture. However, in case of rupture from upper uterine segment, symptoms can be vague and misleading as was in this case. Index patient had presented with complaints of dull aching lower abdominal pain. It was with the help of clinical acumen and added advantage of bedside ultrasound that helped to make a prompt diagnosis right at the time of admission, which proved a boon to save the file of this parturient.

Rupture from the upper uterine segment results in accumulation of blood in peritoneal cavity and can present with abdominal distension and hemoperitoneum as was seen in this case. Treatment of choice for uterine rupture is emergency surgical intervention with resuscitative measures. Aim should be to control bleeding with repair of anatomical defect or proceed with subtotal or total hysterectomy. Intractable bleeding can also be controlled by timely ligation of bilateral uterine arteries or anterior division of internal iliac arteries. Maternal and perinatal mortality have been found to be high following rupture of unscarred area of uterus as well $(30.8 \%$ and $53.8 \%$ respectively) [5].

\section{Conclusion:}

An increase in the rate of uterine rupture, particularly due to raised caesarean deliveries and induction of labor has been observed in recent times. The patients with mismanaged labor, grand multiparas, obstructed and prolonged labor must be managed by trained personnel at an equipped center of excellence. At the present time when Sustainable Development Goal (SDG) aims to reduce maternal mortality ratio (MMR) to less than 70 per 1 lakh live births, it is our duty to strengthen our obstetric care even at grassroot levels. In this context, early diagnosis and immediate intervention can only help to save the life of such a parturient woman.

\section{References:}

1. Dow M, Wax JR, Pinette MG, Blackstone J, Cartin A. Third-trimester uterine rupture without previous caesarean: a case series and review of literature. Am J Perinatol. 2009;26(10):739

2. Zwart JJ, Richters JM, Ory F, de Vries JI, Bloemenkamp $\mathrm{KW}$, van Roosmalen $\mathrm{J}$. Uterine rupture in The Netherlands: a nationwide population-based cohort study. BJOG. 2009;116(8):1069

3. Peplin M, Schwarze U, Superti-Furga A, Byers PH. Clinical and genetic features of 
Ehlers-Danlos syndrome type IV, the vascular type. N Engl J Med. 2000;342 (10):673

4. Khabbaz AY, Usta IM, El-Hajj MI, AbuMusa A, Seound M, Nassar AH. Rupture of an unscarred uterus with misoprostol induction: case report and review of literature. J Matern Fetal Med. 2001; 10 (2): 141

5. Vernekar M, Roy R. Unscarred uterine rupture: A retrospective analysis. J Obstet Gynecol India. 2016;66(1):51-54 